\title{
Gas-Phase Basicities of Serine and Dipeptides of Serine and Glycine
}

\author{
John W. McKiernan, Christina E. A. Beltrame, and Carolyn J. Cassady \\ Department of Chemistry, Miami University, Oxford, Ohio, USA
}

\begin{abstract}
The gas-phase basicities of serine and dipeptides containing amino acid residues of serine and glycine were determined by proton transfer reactions in a Fourier transform ion cyclotron resonance mass spectrometer. The gas-phase basicity (GB) of L-serine was found to be $205.9 \mathrm{kcal} / \mathrm{mol}$, with addition of a hydroxymethyl group $\left(-\mathrm{CH}_{2} \mathrm{OH}\right)$ increasing the basicity by $4.5 \mathrm{kcal} / \mathrm{mol}$ relative to the simplest amino acid glycine $(\mathrm{GB}=201.4 \mathrm{kcal} / \mathrm{mol})$. This is attributed to a combination of intramolecular hydrogen bonding, induction, and symmetry effects. For the dipeptides, addition of a hydroxymethyl group does not result in a large increase in basicity relative to the basicity of glycylglycine ( $G B=208.0 \mathrm{kcal} / \mathrm{mol})$. The gas-phase basicities determined for glycyl-L-serine, L-serylglycine, and L-seryl-L-serine are $209.3,210.6$, and $210.9 \mathrm{kcal} / \mathrm{mol}$, respectively. In comparison to glycylglycine, addition of the hydroxymethyl group at the $\mathrm{N}$ terminus has a greater impact on basicity than its placement at the $C$ terminus. These data suggest that the protonation site for these dipeptides is the N-terminal amino nitrogen. (J Am Soc Mass Spectrom 1994, 5, 718-723)
\end{abstract}

S everal recent studies have focused on determinations of the gas-phase basicities ( $-\Delta G$ of protonation) and proton affinities ( $-\Delta H$ of protonation) of amino acids [1-6], amino acid amides [7], and small peptides [8-11]. These investigations provide fundamental information about structural and thermodynamic aspects of the proton transfer process in the absence of solvents. This is important because protonation plays a major role in the chemistry of peptides: the locations of basic sites impact their hydrogen bonding, three-dimensional structure, and biological activity [12]. In addition, the mass spectral analysis of peptides, including ionization and dissociation, is affected by basicity and protonation site [13, 14].

Recently, the gas-phase basicities (GB) of polyglycines that contain one through six residues were determined in our laboratory by proton transfer reactions in a Fourier transform ion cyclotron resonance (FT-ICR) mass spectrometer [8]. This study also employed high level ab initio calculations to probe the thermodynamics and structures involved in the protonation of glycine and glycylglycine (diglycine). Glycine is the simplest amino acid with a central carbon, which is bound to the amino and carboxylate groups, containing two hydrogen substituents. Polyglycines were chosen for our initial research on peptide hasicities because they are considered to be the backbone of peptides: more complex species are being formed by the addition of functional groups at methylene sites. The present study expands upon this research by replacing

Address reprint requests to Carolyn J. Cassady, Department of Chem istry, Miami University, Oxford, OH 45056. one hydrogen at various methylene sites with a hydroxymethyl group $\left(-\mathrm{CH}_{2} \mathrm{OH}\right)$ to produce serine and dipeptides of serine and glycine.

\section{Experimental}

All experiments were performed using a Bruker (Billerica, MA) CMS-47X Fourier transform ion cyclotron resonance (FT-ICR) mass spectrometer equipped with an external ion source and a 4.7-T superconducting magnct [15]. Protonated amino acid and peptide ions were produced in the external source using a Phrasor Scientific (Duarte, CA) fast-atom bombardment (FAB) gun [16] that employs a $6-10-\mathrm{kV}$ beam of xenon atoms and ions. The biomolecules were dissolved in glycerol with trifluoroacetic acid added as necessary to increase ion abundance.

Ions were transferred from the external source into the FT-ICR mass spectrometer cell by electrostatic focusing. Three stages of differential pumping allowed a pressure in the source of $10^{-4}$ torr, while the base pressure in the cell remained at $1 \times 10^{-9}$ torr. Following ion transfer, thermalization of the trapped ions was achieved by admitting a pulse of argon into the cell vacuum chamber via a General Valve Corp. Series 9 pulsed solenoid valve (Fairfield, NJ). The pulse pressure reached a maximum of $10^{5}$ torr. At least $0.5 \mathrm{~s}$ was allowed for collisional cooling of the ions [17] and for the argon to be pumped away before monitoring ion-molecule reactions.

The protonated peptide ions $\left(\mathrm{MH}^{+}\right)$were massselected by resonant frequency ejection techniques [18] and allowed to react with static pressures of reference 
compounds in the range of $(3-30) \times 10^{-8}$ torr. Overall biomolecular rate constants $\left(k_{\text {all }}\right)$ were determined by observing the pseudo-first-order change in reactant ion intensity as a function of time at a constant pressure. First-order decay plots were linear, which suggests the predominance of ground state reactant ions. In cases where protonation was in competition with another primary reaction pathway (e.g., proton-bound dimer formation), the rate constant for the protonation pathway $\left(k_{\text {proton }}\right)$ was obtained from a plot of the relative protonated reference base $\left(\mathrm{BH}^{+}\right)$intensity as a function of time using [19]

$$
\left[\mathrm{BH}^{+}\right]_{t} /\left[\mathrm{MH}^{+}\right]_{0}=\left(k_{\text {proton }} / k_{\mathrm{all}}\right)\left[1-\exp \left(-k_{\mathrm{all}} t\right)\right]
$$

Experimental rate constants were reproducible to at least $\pm 25 \%$ (relative standard deviation). Pressures were measured with an ionization gauge that was calibrated using the reaction

$$
\mathrm{CH}_{4}^{+}+\mathrm{CH}_{4} \rightarrow \mathrm{CH}_{5}^{+}+\mathrm{CH}_{3}
$$

with a rate constant of $1.335 \times 10^{-9} \mathrm{~cm}^{3} /$ molecule $\cdot \mathrm{s}$, as the reference [20]. Pressures were corrected for the reactant gas ionization efficiency [21], which involved polarizabilities calculated by atomic hybrid parameters procedures [22]. Reported reaction efficiencies are the ratio of the experimental proton transfer rate constant $\left(k_{\text {proton }}\right)$ to the collisional rate constant that was obtained using the average dipole orientation model $\left(k_{\mathrm{ADO}}\right)$ [23]: Reaction efficiency $=\left(k_{\text {proton }} / k_{\mathrm{ADO}}\right)$. The FT-ICR mass spectrometer cell was maintained at room temperature $(\sim 298 \mathrm{~K})$ during all experiments.

\section{Results and Discussion}

The gas-phase basicities of L-serine (Ser), glycyl-Lserine (Gly-Ser), L-serylglycine (Ser-Gly), and Lseryl-L-serine (Ser-Ser) were obtained by deprotonation of FAB-generated, collisionally cooled $\mathrm{MH}^{+}$with a series of neutral reference compounds (B) of known gas-phase basicity:

$$
\mathrm{MH}^{+}+\mathrm{B} \rightarrow \mathrm{M}+\mathrm{BH}^{+}
$$

This was the only major process observed, with the exception of proton-bound dimer $\left(\mathrm{MHB}^{+}\right)$formation for the dipeptides when the reaction was near thermoneutral [8]. Typical mass spectra are shown in Figure 1 for the reactions of (Ser-Gly) $\mathrm{H}^{+}$with pyridine. In this example, proton transfer occurs with a rate constant of $8.0( \pm 1.4) \times 10^{10} \mathrm{~cm}^{3} /$ molecule $\cdot s$ and a reaction efficiency of $0.52(\sim 52 \%$ of all collisions resulting in proton transfer). The rate of proton transfer generally increases with increasing reaction exoergicity, whereas endoergic reactions do not occur or proceed at very low rates [24-26]. For the reaction of Figure 1, the high efficiency indicates an exoergic pro-

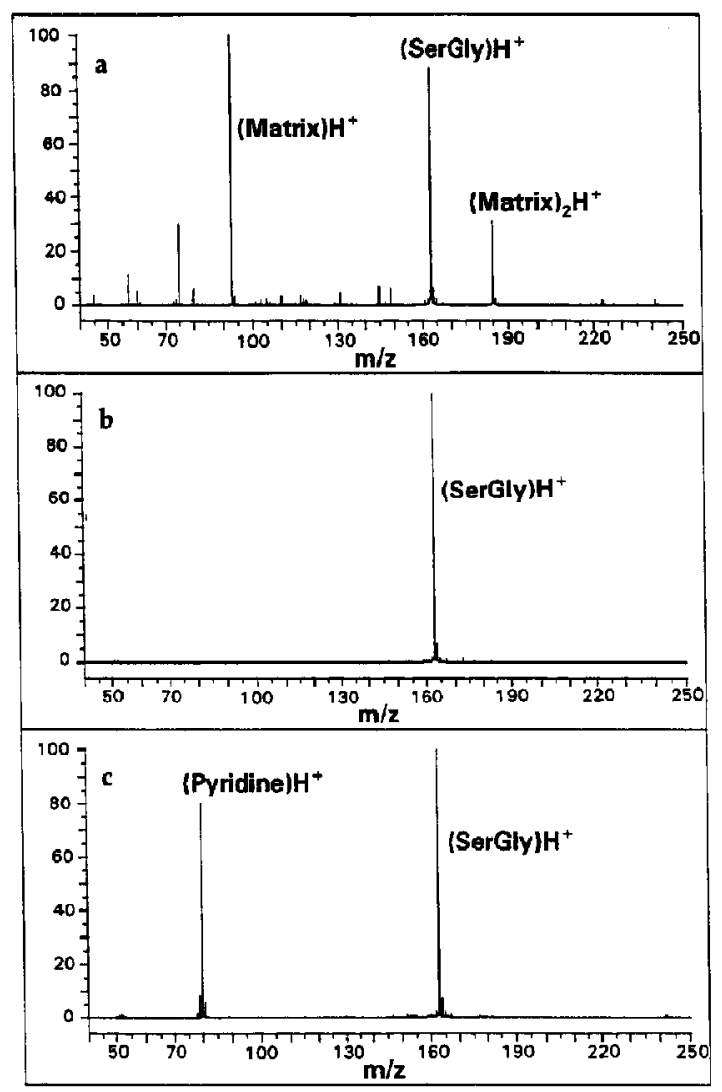

Figure 1. FT-ICR mass spectra for the reaction of (Ser-Gly) $\mathrm{H}^{+}$ with pyridine at a static pressure of $3.4 \times 10^{-8}$ torr. (a) Ion production by FAB on a solution of Ser-Gly in glycerol (matrix). (b) Isolation of (Ser-Gly) $\mathrm{H}^{+}$by swept frequency ejections techniques. (c) Reaction of $(\mathrm{Ser}-\mathrm{Gly}) \mathrm{H}^{+}$with pyridine for $0.5 \mathrm{~s}$.

cess and brackets $\mathrm{GB}$ (Ser-Gly) $<\mathrm{GB}$ (pyridine). In our studies, a reaction efficiency criterion of 0.10 was employed as the break between slow (endoergic) and facile (exoergic) deprotonation reactions [8]. The gasphase basicity of the biomolecule was assigned at this point. This reaction efficiency criterion was utilized previously $[8,26]$ and is necessary because slightly endoergic reactions may occur, but in low efficiencies, in FT-ICR studies. In addition, an efficiency near 0.10 generally marks a sharp transition between the observation of very slow reactions and rapid reactions.

The reference compounds employed, their gas-phase basicities, and the measured efficiencies for reactions involving serine and the three dipeptides can be found in Table 1. To facilitate comparisons, data previously obtained in our laboratory [8] for the proton transfer processes of glycine (Gly) and glycylglycine (Gly-Gly) are also given in Table 1 . Table 2 summarizes the gas-phase basicity and proton affinity values derived from the data in Table 1. Uncertainties reported in Table 2 are the difference in gas-phase basicities between the biomolecule and its bracketing reference 
Table 1. Reaction efficiencies for the proton transfer reactions of protonated biomolecules with reference compounds

\begin{tabular}{|c|c|c|c|c|c|c|c|}
\hline \multirow[b]{2}{*}{ Reference compound } & \multirow[b]{2}{*}{$\mathrm{GB}^{\mathrm{a}}(\mathrm{kcal} / \mathrm{mol})$} & \multicolumn{6}{|c|}{ Reaction efficiency } \\
\hline & & Gly & Ser & Gly-Gly & Gly-Ser & Ser-Glv & Ser-Ser \\
\hline \multirow[t]{2}{*}{ Pyrrole } & 200.3 & 0.01 & 0.03 & 0.01 & 0.00 & 0.00 & 0.00 \\
\hline & & Break $^{c}$ & & & & & \\
\hline Aniline & 202.5 & 0.24 & $-^{d}$ & 0.01 & - & - & - \\
\hline 2-Fluoropyridine & 202.8 & 0.34 & 0.01 & 0.01 & 0.01 & 0.01 & 0.02 \\
\hline$N, N$-Dimethylformamide & 203.6 & 0.33 & 0.04 & 0.04 & 0.02 & 0.01 & 0.01 \\
\hline \multirow[t]{2}{*}{ 3-Methylaniline } & 205.6 & 0.68 & 0.02 & 0.04 & 0.02 & 0.02 & 0.01 \\
\hline & & & Break & & & & \\
\hline 3-Fluoropyridine & 206.2 & 0.76 & 0.16 & 0.03 & 0.02 & 0.03 & 0.04 \\
\hline \multirow[t]{2}{*}{ Allylamine } & 207.9 & 0.61 & 0.59 & 0.07 & 0.04 & 0.02 & 0.02 \\
\hline & & & & Break & & & \\
\hline \multirow[t]{2}{*}{ Ethylamine } & 208.5 & - & 0.63 & $0.20^{\circ}$ & 0.08 & 0.04 & 0.03 \\
\hline & & & & & Break & & \\
\hline \multirow[t]{2}{*}{ n-Propylamine } & 210.1 & - & 0.53 & 0.66 & 0.23 & 0.03 & 0.04 \\
\hline & & & & & & Break & Break \\
\hline i-Propylamine & 211.0 & - & 0.98 & 0.79 & 0.52 & 0.11 & 0.11 \\
\hline Pyridine & 213.1 & - & - & 0.85 & 0.94 & 0.52 & 0.14 \\
\hline Cyclohexylamine & 213.4 & - & - & 1.07 & 0.99 & 0.93 & 0.53 \\
\hline 3-Methylpyridine & 216.2 & - & - & - & 1.15 & 1.10 & 1.11 \\
\hline
\end{tabular}

compounds plus an additional $2.0 \mathrm{kcal} / \mathrm{mol}$ to account for experimental error in the literature basicity values. (That is, subtracting $2.0 \mathrm{kcal} / \mathrm{mol}$ from each of the uncertainties reported in Table 2 gives the uncertainty of our measurement that is independent from errors associated with the literature basicity values.) These uncertainties relate to assignment of absolute gas-phase basicity values and not to the relative order of basicities for the compounds involved in this study. As the data in Table 1 indicate, each biomolecule was reacted with at least four compounds of higher basicity; this allows confirmation of relative basicity assignments by comparisons of several exoergic reaction efficiencies.

Proton affinities reported in Table 2 were obtained by adding $T \Delta S$ terms to the experimentally determined gas-phase basicities. The $T \Delta S$ values were acquired from ab initio calculations on the N-protonation

Table 2. Experimental gas-phase basicities and proton affinities for glycine, serine, and dipeptides of serine and glycine

\begin{tabular}{lcc}
\hline Compound & GB $^{\text {a }}(\mathrm{kcal} / \mathrm{mol})$ & $\mathrm{PA}^{\text {A }}(\mathrm{kcal} / \mathrm{mol})$ \\
\hline \hline Glycine $^{\mathrm{b}}$ & $201.4 \pm 3.1$ & 208.7 \\
L-Serine & $205.9 \pm 2.3$ & 213.2 \\
Glycylglycine $^{\mathrm{b}}$ & $208.0 \pm 2.3$ & 216.3 \\
Glycyl-L-serine & $209.3 \pm 2.8$ & 217.6 \\
L-Serylglycine & $210.6 \pm 2.5$ & 218.9 \\
L-Seryl-L-serine & $210.9 \pm 2.5$ & 219.2 \\
\hline
\end{tabular}

"All values are referenced to the $\mathrm{GB}$ and PA ladders of ref 27

${ }^{b}$ Glycine and glycylglycine data are from ref 8 , but adjusted to the $\mathrm{GB}$ and $\mathrm{PA}$ ladders of ref 27 . of glycine and Gly-Gly [8]. The use of these values assumes agreement, to within experimental error, between the entropy terms for glycine and serine and between the entropy terms of Gly-Gly and the serinecontaining dipeptides. This assumption may result in proton affinity values that are low by up to 1.0 $\mathrm{kcal} / \mathrm{mol}$. The assumption is reasonable because addition of a hydroxylmethyl group is expected to increase the entropies slightly; however, this increase cannot be very large because the entropy term of Gly-Gly is only $1.0 \mathrm{kcal} / \mathrm{mol}$ larger than the entropy term for glycine [8]. That is, addition of an entire glycyl residue increases the entropy by only $1.0 \mathrm{kcal} / \mathrm{mol}$ even though intramolecular hydrogen bonding is involving in Gly-Gly. Therefore, addition of the smaller hydroxylmethyl group should have less of an impact on entropy than $1.0 \mathrm{kcal} / \mathrm{mol}$.

All values in Tables 1 and 2 are referenced to the gas-phase basicity and proton affinity compilation of Lias et al. [27], which assigns ammonia a gas-phase basicity of $195.6 \mathrm{kcal} / \mathrm{mol}$ and a proton affinity of 204.0 $\mathrm{kcal} / \mathrm{mol}$. Two recent studies have suggested that the values in this compilation are low for compounds more basic than ammonia. Meot-Ner and Sieck [28] have proposed that this scale be revised upward by 5-8 $\mathrm{kcal} / \mathrm{mol}$ over the basicity region employed in the present study. In contrast, Szulejko and McMahon [29] have proposed a 1-3-kcal/mol upward adjustment in this region. Because these studies give conflicting results as to the magnitude of the upward revision, we have chosen to reference our values to the currently 
accepted ladder of Lias et al. [27]. Literature values discussed in the text also have been adjusted to conform to this ladder. If this ladder is revised at a future date, our values from Table 2 readily can be modified because their placement relative to the basicities of the reference compounds in Table 1 will remain unchanged. The gas-phase basicities of serine and the dipeptides studied here span only a range of $\sim 5$ $\mathrm{kcal} / \mathrm{mol}$; therefore, differences in basicities between these compounds will vary little even if the absolute basicities are adjusted upward.

Deprotonation reactions yield a gas-phase basicity of $205.9 \pm 2.3 \mathrm{kcal} / \mathrm{mol}$ for serine, from which a proton affinity of $213.2 \mathrm{kcal} / \mathrm{mol}$ is derived. This is in excellent agreement with a gas-phase basicity value of $205.9 \pm 2.6 \mathrm{kcal} / \mathrm{mol}$ obtained by Gorman et al. [1] from proton transfer reactions of laser-generated serine ions and neutrals. Our values also generally agree with a gas-phase basicity of $209.0 \mathrm{kcal} / \mathrm{mol}$ obtained by equilibrium measurements [27] and a proton affinity of $215.0 \pm 0.8 \mathrm{kcal} / \mathrm{mol}$ acquired by the kinetic method of collision-induced dissociation on a proton-bound dimer [2].

The gas-phase basicity of serine is $4.5 \mathrm{kcal} / \mathrm{mol}$ higher than that of glycine, which indicates that addition of a hydroxymethyl group (to form serine) has a significant impact on the thermodynamics of the proton transfer process. Experimental and ab initio results have revealed that the preferred protonation site of glycine is the amino nitrogen [8]. Given that the gasphase basicity of serine is more consistent with an amine rather than an alcohol [27], we conclude that serine is also protonated at the amino nitrogen. The increased basicity of serine relative to glycine is attributable to several effects. First, intramolecular hydrogen bonding may occur between the amino group and the hydroxyl group. Experimental [30] and ab initio [31] studies have indicated that intramolecular hydrogen bonding is present in protonated 1,2aminoethanol ions $\left(\mathrm{H}_{3} \mathrm{NCH}_{2} \mathrm{CH}_{2} \mathrm{OH}^{+}\right)$; this leads to a basicity increase of $3.3 \mathrm{kcal} / \mathrm{mol}$ relative to the basicity of n-propylamine [27]. Because serine and 1,2aminoethanol both have two carbons separating the amino nitrogen and the hydroxyl oxygen, they may experience similar intramolecular hydrogen bonding. These compounds may also derive stabilization of the positive charge on the amino group by induclive effects with the hydroxymethyl group [32, 33]. In addition, symmetry effects may increase the difference in basicity between serine and glycine. Glycine has a plane of symmetry that enhances the stability of its neutral [8]. This symmetry is lost when a proton is added, making protonation slightly unfavorable (relative to a similar molecule with no symmetry) and decreasing the basicity of glycine. Serine is asymmetrical and therefore its basicity is not lowered by this effect.

Glycylglycine has a second amino acid residue to provide stabilization of the proton by intramolecular hydrogen bonding, polarizability, and inductive effects and no plane of symmetry to be lost by addition of a functional group [8]. Therefore, addition of a hydroxymethyl group to $\mathrm{Gly}$-Gly has a less pronounced impact on basicity than it did for glycine. The gas-phase basicity of Gly-Ser is $209.3 \pm 2.3 \mathrm{kcal} / \mathrm{mol}$, which represents an increase of only $1.3 \mathrm{kcal} / \mathrm{mol}$ relative to the gas-phase basicity of Gly-Gly. Ab initio calculations have revealed that the preferred protonation site for Gly-Gly is the amino nitrogen with significant intramolecular hydrogen bonding to the amide carbonyl oxygen [8]. Given the similarity in basicities between Gly-Gly and Gly-Ser, it is reasonable to conclude that Gly-Ser is also protonated at the amino nitrogen. Our results indicate that addition of the hydroxymethyl group to a site four atoms removed from the protonation site has a relatively minor impact on the thermodynamics of protonation. This suggests that this remote group does little to stabilize the charge by polarizability or inductive effects and that intramolecular hydrogen bonding between the amino and hydroxyl groups does not occur. In contrast, 1,6aminohexanol, which enjoys added stability from intramolecular hydrogen bonding, is $4.3 \mathrm{kcal} / \mathrm{mol}$ more basic than hexylamine [33]. (It would be more appropriate to compare the basicity of these dipeptides to 1,5-aminopentanol because the same number of atoms separate the amino and hydroxyl groups; however, the gas-phase basicity of 1,5-aminopentanol has not heen reported in the literature.)

For Gly-Ser, as well as Ser-Ser, an additional argument against intramolecular hydrogen bonding involving the hydroxylmethyl group and the N-terminal amino group is that the hydroxyl oxygen is not the most basic site on the $\mathrm{C}$ terminus. A more basic $\mathrm{C}$ terminal site, and therefore a more favorable site for intramolecular hydrogen bonding, is the carboxyl carbonyl oxygen (e.g., acetic acid is $1.5 \mathrm{kcal} / \mathrm{mol}$ more basic than ethanol [27]). Intramolecular hydrogen bonding between the amino nitrogen and this carboxylate oxygen cannot be ruled out. Although our recent $\mathrm{ab}$ initio calculations [8] have found the most stable $\left(\mathrm{Gly}-\mathrm{Gly} \mathrm{H}^{+}\right.$structure has only intramolecular hydrogen bonding between an amino hydrogen and the amide carbonyl oxygen, a second stable structure that is $0.47 \mathrm{kcal} / \mathrm{mol}$ higher in energy has intramolecular hydrogen bonding of one terminal amino hydrogen to the amide carbonyl oxygen and a second amino hydrogen to the carboxyl carbonyl oxygen [8].

The gas-phase basicity of Ser-Gly is $210.6 \pm 2.5$ $\mathrm{kcal} / \mathrm{mol}$, which indicates that addition of the hydroxymethyl group at the N-terminal methylene carbon of Gly-Gly increases the basicity by $2.6 \mathrm{kcal} / \mathrm{mol}$. Hence, substitution at the carbon $\alpha$ position to the protonation site has a larger impact on basicity than substitution at a remote carbon. [That is, placement of the more basic amino acid residue serine at the $\mathrm{N}$-terminus (Ser-Gly) has a greater impact on basicity than its placement at the $C$ terminus (Gly-Ser).] This can be 
attributed to increased stabilization of the positive charge through intramolecular hydrogen bonding, as has been discussed for serine. In addition, inductive interactions with the adjacent hydroxymethyl group are possible. An analogous effect is seen for aliphatic amines; for example, considering addition of a methyl group to $n$-propylamine, substitution at the carbon $\alpha$ position to the amino group ( $s$-butylamine) increases the gas-phase basicity by $1.6 \mathrm{kcal} / \mathrm{mol}$, whereas substitution at the most remote carbon ( $n$-butylamine) increases the basicity by only $0.5 \mathrm{kcal} / \mathrm{mol}$ [27]. Gorman and Amster [11] have observed a similar effect for dipeptides containing valine combined with alanine (e.g., Val-Ala is more basic than Ala-Val), methionine, and proline, but have found no basicity change when the order of residues is reversed for several other valine-containing dipeptides.

In comparison to Ser-Gly, addition of a second hydroxymethyl group at the $C$ terminus (Ser-Ser) has almost no impact on the basicity of the dipeptide. Ser-Ser has a gas-phase basicity of $210.9 \pm 2.5$ $\mathrm{kcal} / \mathrm{mol}$. This again suggests that the protonation site is the N-terminal nitrogen. As was found for Gly-Ser, a remote hydroxylmethyl group has little involvement in charge stabilization.

Addition of a glycine residue to glycine, to produce Gly-Gly, increases the basicity by at least $6.6 \mathrm{kcal} / \mathrm{mol}$. In fact, $\mathrm{ab}$ initio calculations and experimental results referenced to the Meot-Ner basicity ladder [28] suggest an even greater difference of $8.9-9.1 \mathrm{kcal} / \mathrm{mol}$ [8]. In contrast, a more modest increase $(3.4-4.7 \mathrm{kcal} / \mathrm{mol})$ is seen when a glycine residue is added to serine (Ser-Gly or Gly-Ser). Here, some major factors that enhance the basicity of Gly-Gly relative to glycine - polarizability and inductive effects and a plane of symmetry for glycine-are either absent or muted. Because neither serine nor its dipeptides has a plane of symmetry, symmetry has no impact on the relative basicities of these species. In serine, the protonation site already experiences charge-stabilizing effects from the hydroxymethyl group; this may offset the impact of stabilization from a second amino acid residue. In other words, the $6.6-\mathrm{kcal} / \mathrm{mol}$ increase in basicity between glycine and Gly-Gly is unique; other dipeptides are not expected to exhibit a similar increase relative to the gas-phase basicities of their component amino acids. This is supported by a study of 22 valine-containing dipeptides where increases in gas-phase basicity between the dipeptide and the most basic amino acid residue only ranged from 0 to $4.5 \mathrm{kcal} / \mathrm{mol}$ [11].

The study by Gorman and Amster [11] of 22 valine-containing dipeptides suggests that, in general, the basicity of a dipeptide is equal to that of its most basic residue regardless of the basic residue's position in the dipeptide. This generalization does not apply for Gly-Gly, Gly-Ser, Ser-Gly, or Ser-Ser. Although the differences in basicity found in the present study are only a few kilocalories per mole, they are readily measurable. Serine and glycine are two of the least basic amino acids [1-5]. It is possible that the generalization is more appropriate for higher basicity amino acids. Higher basicity amino acids already have side chains that provide considerable stabilization of the positive charge. This may almost totally negate the impact of charge-induced dipole and inductive stabilization that is achieved when an additional amino acid residue is added to produce a dipeptide.

\section{Conclusions}

Proton transler reactions involving FAB-generated collisionally cooled ions in an external source FT-ICR mass spectrometer provide a convenient method for determining the gas-phase basicities of low volatility compounds. By choosing reference compounds of appropriate basicity and measuring reaction rate constants, small differences in gas-phase basicity can be discerned. For Ser, Gly-Ser, Ser-Gly, and Ser-Ser, this method yielded gas-phase basicity values of 205.9, $209.3,210.6$, and $210.9 \mathrm{kcal} / \mathrm{mol}$, respectively. The presence of a hydroxymethyl group $\left(-\mathrm{CH}_{2} \mathrm{OH}\right)$ on serine increases the basicity by $4.5 \mathrm{kcal} / \mathrm{mol}$ relative to that of glycine (GB $=201.4 \mathrm{kcal} / \mathrm{mol}$ ). This is attributed to stabilization of the positive charge intramolecular hydrogen bonding and inductive effects with the hydroxylmethyl group, as well as symmetryrelated effects. The dipeptides studied here were all sufficiently more basic than their most basic amino acid component. Also, in comparison to the simple dipeptide Gly-Gly $(\mathrm{GB}=208.0 \mathrm{kcal} / \mathrm{mol}$ ), addition of the hydroxylmethyl group at the $\mathrm{N}$ terminus (Ser-Gly and Ser-Ser) has a greater impact on basicity than its placement at the $\mathrm{C}$ terminus (Gly-Ser). This suggests that an N-terminus hydroxylmethyl group has little involvement in charge stabilization, which leads to the conclusion that the protonation site of these dipeptides is the N-terminal amino nitrogen.

\section{Acknowledgments}

Financial support by the National Institutes of Health (R15GM47657-01A1) and the Ohio Board of Regents Academic Challenge Program is gratefully acknowledged.

\section{References}

1. Gorman, G. S.; Speir, J. P.; Tumer, C. A.; Amster, I. J. J. Am Chem. Soc. 1992, 114, 3986

2. Li, X.; Harrison, A. G. Org. Mass Spectrom. 1993, $28,366$.

3. Wu, Z.; Fenselau, C. Rapid Commun. Mass Spectrom. 1992, 6, 403

4. Isa, K.; Omote, T.; Amaya, M. Org. Mass Spectrom. 1990, 25, 620.

5. Bojesen, G. J. Am. Chem. Soc. 1987, 109, 5557.

6. Bliznyuk, A. A.; Schaefer, H. F.; Amster, I. J. J. Am. Chem. Soc. 1993, 115, 5149 .

7. Kinser, R. D.; Ridge, D. P. Proceedings of the 40th ASMS Conference on Mass Spectrometry and Allied Topics; Washington, DC, June 1, 1992; pp 75-76.

8. Zhang, K.; Zimmerman, D. M.; Chung-Phillips, A.; Cassady, C. J. I. Am. Chem. Soc. 1993, 115, 10812. 
9. Wu, Z.; Fenselau, C. J. Am. Soc. Mass Spectrom. 1992, 3, 863. 10. Wu, J.; Lebrilla, C. B. I. Am. Chem. Soc. 1993, 115, 3270.

11. Gorman, G. S.; Amster, I. J. I. Am. Chem. Soc. 1993, 115, 5729.

12. MoCammon, J. A.; Harvey, S. C. Dynamics of Proteins and Nucleic Acids; Cambridge University Press: Cambridge, 1987.

13. Sunner, J.; Morales, A.; Kebarle, P. Anal. Chem. 1987, 59. 1378.

14. Hunt, D. F.; Yates, J. R., III; Shabanowitz, J.; Winston, S.; Hauer, C. R. Proc. Natl. Acad. Sci. USA 1986, 83, 6233.

15. Kofel, P.; Allemann, M.; Kellerhals, H. P.; Wanczek, K. P. Int. J. Mass Spectrom. Ion Process. 1985, 65, 97.

16. Perel, J;; Faull, K.; Mahoney, J. F.; Tyler, A. N.; Barchas, J. D. Am. Lab. 1984, Nov, 94.

17. Ahmed, M. S.; Dunbar, R. C. J. Am. Chem. Soc. 1987, 109, 3215 .

18. Comisarow, M. B.; Grassi, V.; Parisod, G. Chem. Phys. Lett. 1978, 57, 413.

19. Espenson, J. H. Chemical Kinetics and Reaction Mechanisms; McGraw-Hill: New York, 1981; p 55.

20. Bartmess, J. E. In Structure/Renctioity and Thermochemistry of Ions; Ausloos, P.; Lias, S. G., Eds.; Reidel: Dordrecht, The Netherlands, 1987; pp 367-371.

21. Bartmess, J. E.; Georgiadis, R. M. Vacuum 1983, 333, 149.
22. Miller, K. J. J. Am. Chem. Soc. 1990, 112, 8533.

23. Su, T.; Bowers, M. T. Int. ]. Mass Spectrom. Ion Phys. 1973, 12, 347.

24. Lias, S. G.; Shold, D. M.; Ausloos, P. J. Am. Chem. Soc. 1980, 702, 2540 .

25. Bohme, D. K.; Mackay, G. I.; Schiff, H. I. I. Chem. Phys. 1980, 73, 4976 .

26. Büker, H.-H.; Grützmacher, H.-F. Int. I. Mass Spectrom. Ion Process. 1991, 109, 95.

27. Lias, S. G.; Liebman, J. F.; Levin, R. D. J. Phys. Chem. Ref. Data 1984, 13, 695.

28. Meot-Ner, M.; Sieck, L. W. J. Am. Chem. Soc. 1991, 113, 4448.

29. Szulejko, J. E.; McMahon, T. B. J. Am. Chem. Soc. 1993, 115, 7839.

30. Meot-Ner, M.; Hamlet, P.; Hunter, E. P.; Field, F. H. J. Am. Chem. Soc. 1980, 102, 6393.

31. Houriet, R.; Rufenacht, H.; Carrupt, P.-A.; Vogel, P.; Tichy, M. J. Am. Chem. Soc. 1983, 105, 3417.

32. Taft, R. W. In Progress in Physical Organic Chemistry; Taft, R. W., Ed; John Wiley: New York, 1983; pp 247-350.

33. Aue, D. H.; Bowers, M. T. In Gas Phase Ion Chemistry; Bowers, M. T., Ed.; Academic Press: New York, 1979; pp 1-51. 